\title{
Talking the Talk and Walking the Walk: Designing an Online Admissions Process in an Elearning Training Project
}

\author{
Andrei OGREZEANU \\ University Politehnica of Bucharest, Bucharest, Romania \\ aogrezeanu@gmail.com \\ Cezar SCARLAT \\ University Politehnica of Bucharest, Bucharest, Romania \\ cezarscarlat@yahoo.com \\ Andreea OGREZEANU \\ University Politehnica of Bucharest, Bucharest, Romania \\ ogrezeanu.a@gmail.com
}

\begin{abstract}
This paper presents a case study of the design and implementation of the admissions process in a large teachers elearning training project that took place in Romania. From a theoretical viewpoint we aim at contributing to a rather understudied area at the intersection between project and process management literature. We show that project management could borrow some process management tools and techniques in designing highly repetitive activities. From a practical viewpoint, the case presented could serve as a good practice for other training projects and support them in simplifying admissions procedures by systematic process design and the use of accessible Web technologies.
\end{abstract}

Keywords: process management; project management; elearning; training project; registration-admission process; Romania

\section{INTRODUCTION: LINKS BETWEEN PROJECT AND PROCESS MANAGEMENT}

Both project management and process management disciplines have developed substantially over the past decades. The two areas of study and practice have similarities; however the need to distinguish them has also been often heralded. By definition, the resemblance between the two is that they are both sets of activities oriented toward achieving goals. The main difference however is that processes are repetitive, recurrent sets of activities, that take place over and over again in an organization as part of its core activity (production of products or services) or as part of support activities (e.g. payroll, administrative services, etc.), while projects are unique, one-off sets of activities (Nokes \& Kelly, 2007; Project Management Institute, 2013). Whether activities are organized as projects or processes "depends on whether the organization repeats an activity often 
enough so that it becomes routine" (Nokes \& Kelly, 2007, p. 9) more than on the nature of the activities themselves.

Aside from this legitimate semantic concern of the management literature for distinguishing between processes, and projects and consequently between project management and process management, the two fields have grown rather separately from one another with rather few links being drawn between them. One way the two have been related has been by trying to systematize project management and program management in organizations such that it becomes more process like and becomes embedded in broader organizational, strategic and performance management. For example Fernandes et al. (2015) argue that organizations differ in the extent to which project management is used as a tool for achieving certain goals, versus situations where project management principles and practices become embedded into organizational practices and processes. Thus in the former case, projects may be approached in a more informal and ad hoc manner, while in the later organizations may have formally defined methodologies and a systematic approach to career paths or certification systems in project management. Adler and colleagues (1995) have argued that often product development projects are not that unique as theory may lead us to believe. Rather they have substantial similarities of in activities and flow to allow for a process approach to their management allowing simultaneously for closer monitoring and performance management.

Another link that can be established between process and project management is that the project management literature does make many references to "project management processes", these including initiating processes, planning processes, executing processes, monitoring and controlling processes, closing, etc (Nokes \& Kelly, 2007; Project Management Institute, 2013). However what can be observed is that in these cases, the term process is used, not in the rather specific meaning of the project management literature, but in a broader sense of sequence of actions.

An additional link between project management and process management is that process improvements and process design (in new product development) usually take place within projects with this purpose in mind. The literature in this area abounds with many research pieces discussing mainly the issue of business process improvement, various methodologies and results (e.g. Ittner \& Larcker, 1997; Nair, Malhotra, \& Ahire, 2011; Rohleder \& Silver, 1997; Swink \& Jacobs, 2012), however we cannot but observe that in these cases the link between the two literatures is rather spurious: it is rather a cooccurrence of two areas of management where projects have as purpose process improvement (which tend to be one-off operations, although sometimes reoccurring after a while within renewed projects).

To summarize, process and project management have tended to be linked in a substantive way when projects have been proposed to be subsumed in broader organizational processes or when projects have as objective process management improvement. There has been little use of process management knowledge in project management especially in the area of project activity design, execution, monitoring and control. This aspect is particularly surprising especially since project management literature tends to be somewhat less 
informative especially on activities design. The Project Management Institute's (PMI) $P M B O K$ Guide offers a rather reduced set (albeit useful) of tools and techniques by which the project designer/manager can design activities. Such techniques include: decomposition (splitting work packages into smaller and smaller units) with variants like rolling wave planning (where near term activities are defined in more detail while longer term in higher detail) or expert judgment (where pre-existing expert knowledge is used to define activities) (Project Management Institute, 2013, pp. 151-2).

What seems to be missing is exactly what project management could be borrowing from process management, more systematic ways of analyzing and designing activities that address simultaneously issues such as: who has to act, what action needs to be done, in what order and with which dependencies (the later one admittedly is given much attention in project management).

\section{PURPOSE AND ANALYTIC FRAMEWORK}

This paper has a twofold aim. From a theoretical viewpoint it explores an area where project management activity design could borrow tools and techniques from process management analytical and design methodology, especially in the area of highly repetitive activities. Particularly we make use of the widely used book in the field, Sharp and McDermott's Workflow Modelling... (2009). We show how this analytical framework can be used in approaching process analysis and design especially for highly repetitive activities within projects.

From a more empirical point of view we present a case study of a large technology (ICT/ elearning) training project that took place in Romania between 2010 and 2013 emphasizing one aspect that we believe may represent a good practice that other similar projects may apply. Specifically, we show how the project not only talked about technology use in teaching others about it but made full use of it in order to make a highly bureaucratic process more manageable by both applicants and admissions administrators. We did so by exclusively using open source tools that were relatively easy to implement.

In describing and explaining the process under review we make use of Sharp and McDermott's analytical framework. They proceed from a very simple (and probably incomplete at first) definition of what a process is, that is "a process is a collection of activities (or steps or tasks, or whatever) that is a way to get something done". However Sharp and McDermott insist on several definitional features of processes in the context of process management. We summarize them in what follows:

1. A process "involves work" that is it is a "set of activities or (..) a sequence of steps and decisions, and can be completed by a person or a machine or both" (Sharp \& McDermott, 2009, p. 39)

2. A process, propose Sharp and McDermott, should (be able to) be named in a verbnoun form where the verb is transitive and expresses an action that is being done upon an object represented by the noun. For example acquire new customer could be a process. In the participle form the verb expresses the result of the process, e.g. customer acquired (pp. 39-40). 
3. Delivers a specific and essential result:

a. The result is discrete and identifiable such that individual instances of the result can be differentiated.

b. The result is countable: the various instances, since they are discrete and identifiable can be counted.

c. The result is essential in that "it is fundamentally necessary for the operation of the enterprise, not just a consequence of current implementation" (pp. 40-41).

4. It is initiated by a specific triggering event which can be:

a. Action event - when a person or organization does something;

b. Temporal event - when a predetermined time is reached;

c. Condition or rule event - when a monitoring activity detects an exception condition (p. 44).

Additional business process characteristics:

1. Business processes are measurable, possibly in multiple ways relevant for different stakeholders;

2. Automation: various tasks can be manual or automatic;

3. Levels of detail: processes can be described in different levels of detail as needed. Usually a progression is followed from higher level to lower level descriptions.

4. Customers of processes can be internal or external (pp. 59-60).

In the following section we use the analytic framework provided by Sharp and McDermott in order to present the process that was used for admissions in an eLearning training project.

\section{CASE PRESENTATION}

\section{Context, Scope and Goals}

Our case is represented by the admissions process in a teachers eLearning training project that took place in Romania between August 2010 and July 2013. The project, named shortly eProf ${ }^{1}$ was financed by the European Social Fund and the Romanian Government through the Sectoral Operational Program Development of Human Resources (SOP HRD). Its objectives (now fulfilled) were to train at least 2000 secondary education teachers (of various subjects) in using ICT and specialized eLearning tools in their teaching activity. A secondary objective of the project was to create a Web portal of the project that would serve as: project website, elearning platform, document repository and a media outlet contributing to a digital culture in teaching in Romania. The project was implemented in a partnership made of four organizations: two leading technical universities in Romania, University Politehnica of Bucharest (Parnership leader) and University Gh. Asachi in Iasi (Partner 1), and two IT and management services and consultancy companies Pythia International (Bucharest, Romania, Partner 2) and CSI Piemonte (Torino, Italy, Partner 3). The project admitted secondary education teachers from all regions of Romania and had two training centers in Bucharest (where at least 1400 teachers were to be trained) and Iasi

\footnotetext{
${ }^{1}$ The project's complete name in Romanian was: eProf: Formarea personalului didactic din învăţământul secundar (ISCED 2-3) în vederea utilizării tehnologiei informaţiei si a instrumentelor e-learning în activitatea didactică". See www.eprof.ro.
} 
(where at least 600 teachers were trained). Training took place by means of blended learning where part of the teaching/learning was done from a distance using an eLearning platform and part of it was done with presence at the training centers in fully computer endowed classrooms). ${ }^{2}$

The issue of designing an admissions process came up as a practical issue to be solved within project implementation. To achieve the main goal of the project, that of training teachers, an essential precondition was that such trainees were first registered and admitted for participation in the training (as such the admission process satisfies the essentiality condition stated by Sharp and McDermott). The admissions process faced several regulatory constraints:

1. It had to follow the data and document requirements issued by the project financing authority, the Management Authority of the SOP HRD, a notoriously highly bureaucratic agency.

2. It had to follow the data and document requirements of the training accreditation authority (the National Council for Professional Training of teachers in Romania, a department within the Ministry of Education).

3. It had to follow regulations concerning the use of personal information.

The data and document requirements imposed especially by the financing authority were significant a multitude of paper forms and documents were required as well as reporting in electronic format in complex Excel files about the target group. By following an approach where each document and form were filled separately with a lot of redundant information between forms, the process of applying for course participation the application process would have been highly complicated for both applicant and project operational personnel in charge of admissions. There was thus a desire to simplify as much as possible the admissions process from both the management and operational personnel.

In addition to making the application process easier for those involved there was an explicit concern with project's consistency with its own goals and values. The project was built around promoting digital tools and showing their usefulness in teaching. Teaching state of the art eLearning courses while at the same time having a cumbersome paper based registration/admission process would have been highly inconsistent, and management was concerned that this would negatively impact project's reputation and capacity to attract applicants.

Consequently the goal of designing the admissions process was:

1. Designing a functional admissions process that satisfies project's practical requirements and legal regulatory requirements from multiple regulation agencies;

2. That is simple enough such that it is as easy as possible to follow by applicants, following to the extent possible the principle collect once, use multiple times regarding information gathered.

3. As well as simple for admissions operational personnel;

\footnotetext{
${ }^{2}$ For additional information about the project see the project website, www.eprof.ro, as well as (Ogrezeanu, Ogrezeanu, \& Niculescu, 2015)
} 
4. And which is consistent with the technological goals of the project in making full use of information technology where useful.

\section{Process Automation: Web Application for Managing Admissions}

In order to achieve the goals listed above, it became clear that the admissions process had to be assisted to the extent possible by Information Technology (IT) particularly by means of Web technology. The project portal thus acquired an additional purpose, that of being a management and operational instrument for the project. The portal component (on top of which management and operational functionalities were built) was based on Joomla technology specifically building various forms and reports that allowed for data entry, checking and manipulation.

The following Web functionalities were developed to support the admissions process:

1. Online registration form.

To open the registration form, a website visitor (initially as unregistered guest) had to first create a website user account by simply providing a set of general data such as name, username, County, Town/City, and password. Once registered on the website the user could begin course registration by opening the registration form. Due to the multitude of data and forms required by different regulatory agencies, the online registration form was made of the union of all data fields required by the financing and training accreditation authorities. The result was a rather complex form which was split in several sections: personal information, contact information, professional information, data about teaching school of the applicant, options regarding course participation (training center and preferred sessions). The form contained both open fields filled by typing the answer as well as combo boxes and drop boxes. Some fields were checked for format consistency (for example the Romanian ID Number, CNP). Due to its size, there wasn't any expectation that the applicant would finish filling the form in one session, therefore the partially completed form could be saved and continued later. The completion and submission of the registration form was the triggering event for the admissions process.

2. Application administration form

This form was very similar to the registration form, allowing the admissions operator to visualize and edit registration data. In addition it contained several data fields corresponding to a few decisions:

a) Candidate status (admitted, rejected, withdrawn, etc.)

b) Check marking of a series where the candidate was allocated;

c) Complete file (yes, no)

d) Message sent with completed documents (yes, no)

e) Course participation and completion (graduated, gave up before course start, gave up during course);

f) Observations (open text field).

3. Automated generation of registration documents.

Based on the complete and validated online registration form a set of printable (PDF) registration documents were generated including:

a) Registration form;

b) Training contract 
c) Certificate of being employed at a school (signed by school directorate);

d) Agreement for granting access to personal information;

e) A checklist of all documents needed (in addition to the above a CV, a copy of ID card, were required)

The applicant had to sign documents a, b and c and obtain signature on d, while the ones at $\mathrm{D}$ had to be sent on paper. All printed documents were to be sent physically by the postal service to the selected training center.

4. A series of tables and reports with candidates sorted or filtered by status, training center.

5. Automated generation of confirmation messages and message with documents generated (see 3 above) attached.

6. General administration interface from which the various forms, tables and reports were being accessed.

\section{Process design and description}

Process design took place at the same time as the Web based admissions functionalities were designed. While the Web functionalities described above were meant to support most steps in the process they were designed as a set of discrete functionalities that further needed to be integrated into a process. The wider process was based on a decomposition of the activity of admissions. While the Sharp and McDermott methodology was not directly used in its design, a similar (yet more classic) one was used with classical process diagrams illustrating each step (task), arrow links between them and decision points. The Sharp and McDermott suggested swim lane diagram is more useful in this post factum description and analysis as it provides an easy view of both the steps and who is supposed to fulfill them while at the same time not adding much more detail, not needed in this medium level of detail description.

Figure 1, below, presents the swimlane diagram of the admissions process. One can see that the triggering event was the submission of the registration form by applicants while the end result was a complete file and a candidate committed at least formally to begin a training course session. On can also see that the admissions process interacted with other processes for example it was the management process that established when, where and the type of training sessions and the admissions process needed this as an input. Its output was that the list of admitted candidates and some information about them could be used in the process of physical organization of training sessions (including hotel reservations, catering services, communication with applicants before sessions, etc.) as well as the process of online course creation on the eLearning platform.

\section{Assessment}

The process and web portal functionalities were implemented as described above. They were successfully used during project implementation. More than 6000 registrations were made (most valid) but unfortunately only a little over 2000 could be covered by the project 
(one a first in first out basis) due to limited financing available (for more information on project's outcome see Ogrezeanu, Ogrezeanu, \& Niculescu, 2015). The process and Web functionalities did indeed help a lot with simplifying the admissions bureaucracy for both applicants and admissions operators, making their overall experience of the project more positive.

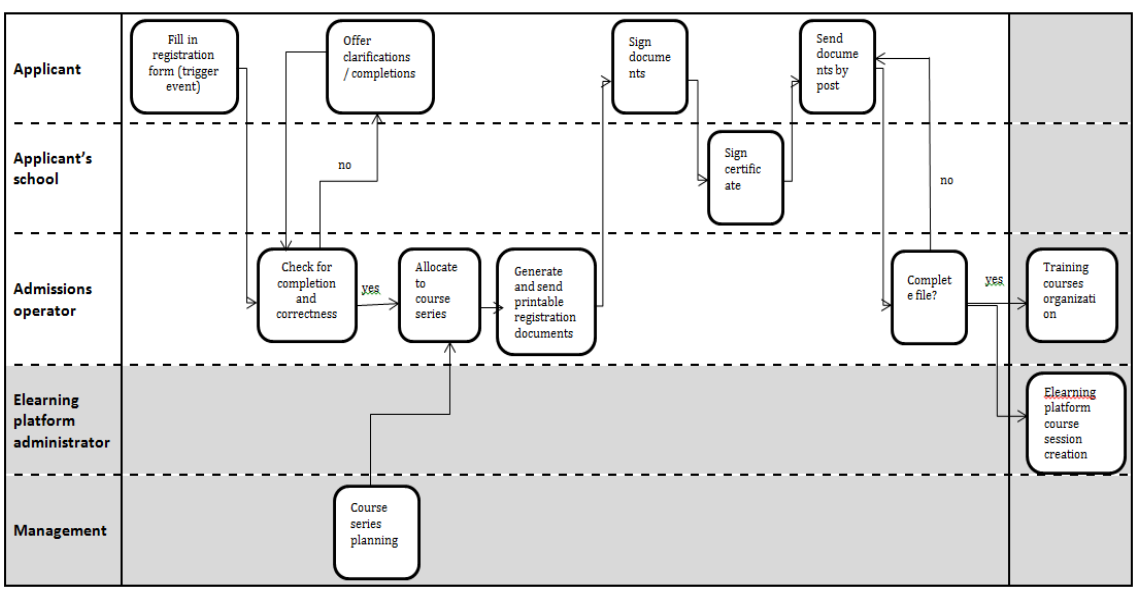

Figure 1: Swimlane diagram of the eProf project admissions process

In addition to the benefits related to the process of admission of candidates itself, there were broader project benefits of using an ICT (Web) supported process. Because the data was introduced non redundantly in electronic format and processed in that form, it could be easily used within the project for other activities and processes. For example, the elearning platform could easily import the data from the Joomla portal's database of applicants depending on how they were allocated to different course series. Also various lists of course participants and relevant data were produced to support the logistics of training series organizations. Finally, and very importantly, the Web portal also supported the automatic production of tables and reports that were highly necessary for project monitoring as well as reporting to the management authority.

\section{CONCLUSION}

This paper has presented a case of the admissions process design within a teachers' eLearning training project that took place in Romania between 2010 and 2013. The need for an approach of systematic process design arose from several requirements:

1. The project's need to have a functional admissions process that could take in thousands of applicants that was as simple and manageable as possible for both applicants and admissions operators;

2. Multiple requirements in terms of necessary data and documents from multiple regulatory agencies; 
3. The need to make the process and the experience of applicants and admissions operators consistent with project's goals and values.

The paper illustrates how a systematic approach borrowed from process management can be used in activity design and implementation in project management, especially for highly repetitive activities within projects. From a theoretical viewpoint this shows that there is a clear area of intersection between project and process management where the former could borrow some of the tools of the later. While projects as a whole are indeed unique, not all of their activities are. Some of their activities are highly repetitive and require a process management approach.

From a practical point of view we presented a tried and tested admissions process that could be used with modifications in other large training projects. We have shown that with a partly automated process supported by simple open source Web tools what could have been a nightmarishly bureaucratic process of admissions could be simplified to a manageable level of complexity.

\section{REFERENCES}

Adler, P. S., Mandelbaum, A., Nguyen, V., \& Schwerer, E. (1995). From Project to Process Management: An Empirically-Based Framework for Analyzing Product Development Time. Management Science, 41(3), pp. 458-484.

Fernandes, G., Ward, S., \& Araújo, M. (2015). Improving and embedding project management practice in organisations - A qualitative study. International Journal of Project Management, 33(5), 1052 - 1067.

Ittner, C. D., \& Larcker, D. F. (1997). The Performance Effects of Process Management Techniques. Management Science, 43(4), pp. 522-534.

Nair, A., Malhotra, M. K., \& Ahire, S. L. (2011). Toward a theory of managing context in Six Sigma process-improvement projects: An action research investigation. Journal of Operations Management, 29(5), 529 - 548.

Nokes, S., \& Kelly, S. (2007). The Definitive Guide to Project Management: The Fast Track to Getting the Job Done on Time and on Budget (2nd ed.). Prentice Hall.

Ogrezeanu, A., Ogrezeanu, A., \& Niculescu, A. (2015). Entrepreneurship and Innovativeness in an eLearning Training Project in Romania. In Proceedings of the 10th European Conference on Innovation and Entrepreneurship - ECIE 2015. Genoa, Italy.

Project Management Institute. (2013). A Guide to the Project Management Body of Knowledge (5th ed.). Newtown Square: Project Management Institute.

Rohleder, T. R., \& Silver, E. A. (1997). A tutorial on business process improvement. Journal of Operations Management, 15(2), 139 - 154.

Sharp, A., \& McDermott, P. (2009). Workflow Modelling: Tools for Process Improvement and Application Development (2nd ed.). Norwood, MA: Artech House.

Swink, M., \& Jacobs, B. W. (2012). Six Sigma adoption: Operating performance impacts and contextual drivers of success. Journal of Operations Management, 30(6), 437 $-453$. 